Garavito, L... (2016). Crecimiento Económico, Empleo y Desarrollo en Colombia (En Minería y Desarrollo, pp. 177-209). Externado de Colombia. Bogotá.

Garay Salamanca, L. J. (2013). Minería en Colombia. Contraloría General de la República. 3 Tomos.

Ghon, M. D. (1997). Teorías dos movimentos sociasis. Paradigmas Classicos. E. Sao Paulo: Edico Loyola.

Giraldo Barbosa, J. E. (2010). Sistema de transporte del carbón: impactos y la evocación frustrada por el choque de trenes (En Las paradojas de una bonanza: Impactos de la actividad carbonera en los departamentos del Cesar y Magdalena, págs. 90-139). Santa Marta, Universidad del Magdalena-Colciencias.

Llinás Vargas, M. (2010). Cómo digerir el “boom” minero-energético. Portafolio. Bogotá.

Negrete Montes, R. E. (2013). Consulta previa: consideraciones constitucionales-perspectiva nacional (En Minería en Colombia, págs.281335). Contraloría General de la República. Bogotá.

Olivero Verbel, J. y Otros (2013). Implicaciones de la minería del carbón en el ambiente y la salud humana: una aproximación abreviada al estado del arte (En Minería en Colombia, págs. 229-242). Contraloría General de la República. Bogotá.

Pardo, L. Á. (2014), Una política integral minera desde la perspectiva de un sistema complejo: hacia un modelo alternativo (En Minería en Colombia, págs.31-77) Contraloría General de la República. Bogotá.

Rudas Lleras, G. (2013). La paradoja de la minería y el desarrollo: análisis departamental y municipal para el caso de Colombia (En Minería en Colombia, págs. 28-84). Contraloría General de la República. Bogotá. 
Capítulo 10

\title{
DEFENSA TÉCNICA EN PROCESOS DE RESPONSABILIDAD FISCAL, EJERCIDA POR LOS ESTUDIANTES DE CONSULTORIO JURÍDICO DE CECAR, COLOMBIA, AÑOS 2016- 2018
}

\author{
Yanith Del Carmen Mayoriano Tovar ${ }^{1}$ \\ Dulfay Del Cristo Monsalve Muñoz \\ Gunkell Romero Gutiérrez ${ }^{3}$
}

\section{Resumen}

El proceso de responsabilidad fiscal es un procedimiento administrativo que realizan las Contralorías, el cual busca determinar la responsabilidad del servidor público o particular cuando estos estén en ejercicio de la gestión fiscal y causen por acción u omisión un detrimento patrimonial al Estado. Luego, los señalados como responsables fiscales requieren la defensa técnica de un abogado que vele por sus derechos e intereses ante las Contralorías. Para ello el legislador facultó a los estudiantes de los consultorios

\footnotetext{
1 Yanith Mayoriano Tovar, Abogada Judicante adscrita al Consultorio Jurídico de CECAR. E-mail: yanith.mayoriano@cecar.edu.co

2 Abogada y Magíster en Derecho de la Universidad de Cartagena. Docente investigadora adscrita al Centro de Investigación Sociojurídica de la Corporación Universitaria del Caribe-CECAR. Email: dulfay.monsalvem@cecar.edu.co.

3 Candidato a Magíster en Gestión Pública, Universidad Nacional del Rosario, Argentina. Especialista en Derecho Administrativo. Abogado. Docente y Asesor de Consultorio Jurídico de la Facultad de Derecho y Ciencias Políticas de CECAR. Miembro del Grupo de Investigación GISCER. Email: gunkell.romero@cecar.edu.co
} 
jurídicos del país para que actúen como apoderados en esta clase de procesos estableciendo que las Contralorías deben solicitar de oficio a los estudiantes cuando la Ley lo disponga. La Contraloría general de la república gerencia departamental Sucre y la Contraloría Departamental de Sucre, durante todos estos años ha solicitado de oficio a los estudiantes del consultorio jurídico de CECAR, nos dedicaremos a analizar la importancia de la defensa técnica realizada por los estudiantes en los procesos de responsabilidad fiscal en los años 2016, 2017 y lo que va corrido del año 2018. Lo anterior realizado bajo un enfoque cualitativo, constituyendo una investigación jurídica de tipo descriptivo, en la que se emplearon fuentes secundarias de información, como leyes, sentencias y principalmente los registros del consultorio jurídico. De esta manera se pudo concluir que la labor de defensa técnica realizada por los estudiantes del consultorio, contando con la guía de los docentes asesores tal como se ha previsto, es importante y necesaria pues se genera un aporte de proyección social a nivel local significativo y de calidad.

Palabras clave: Responsabilidad fiscal, gestión fiscal, estudiantes, defensa técnico, apoderado de oficio.

\section{Abstract}

The fiscal responsibility process is an administrative procedure carried out by the Comptroller's Offices, which seeks to determine the responsibility of the public or private servant when these are in the exercise of fiscal management and cause by action or omission a detrimental patrimonial effect to the State. Then, those identified as tax officials require the technical defense of a lawyer to watch over their rights and interests before the Comptroller's Office. To this end, the legislature empowered students from the country's legal offices to act as attorneys-in-fact in this type of process, establishing that the Comptroller's Office must request the students to act ex officio when the law so provides. The Office of the Comptroller General of the Republic, departmental management of Sucre, and the Office of the Comptroller of the Departments of Sucre, during all these years have ex officio requested the students of CECAR's legal office to analyze the importance of the technical defense carried out by the students in the processes of fiscal responsibility in the years 2016, 2017 and 2018. This was done under a qualitative approach, constituting a descriptive legal research, in which secondary sources of information 
were used, such as laws, judgments and mainly the records of the legal office. In this way it was concluded that the technical advocacy work carried out by the students of the clinic, with the guidance of the consultant teachers as planned, is important and necessary because it generates a significant and quality contribution of social projection at the local level.

Key words: Fiscal responsibility, fiscal management, students, technical defence, ex officio attorney.

\section{Introducción}

El papel que desempeñan los estudiantes de los consultorios jurídicos de las facultades de derecho del país en la sociedad colombiana ha sido en varias ocasiones puesto en tela de juicio. Situación reglamentada por el Decreto 196 de 1971 y modificado por la Ley 583 del 2000, la cual establece en qué eventos los estudiantes de los dos últimos años de las facultades de derecho de las universidades del país pueden ser apoderados judiciales de personas de escasos recursos económicos que no tienen para sufragar los gastos de un abogado particular.

Varios abogados han presentado demandas de inconstitucionalidad solicitando la declaratoria de inexequibilidad por parte de los magistrados de la Corte Constitucional, pero hasta la fecha no ha sido posible. En sentencias como la SU-044 de 1995 y C-626 de 1996 se avaló la exequibilidad de la función de los estudiantes de derecho, concluyendo que es el legislador quien debe determinar los casos en los que se deben exigir títulos de idoneidad para actuar como defensores. Por su parte la sentencia C-143 de 2001 (Corte Constitucional de Colombia, 2001) establece:

La Constitución Política consagra en el artículo 229 el derecho de toda persona para acceder a la administración de justicia y señala además que (La ley indicará en qué casos podrá hacerlo sin representación de abogado). Y si se faculta al legislador para señalar en qué casos puede accederse a la administración de justicia sin representación de abogado, con mayor razón puede el legislador indicar las situaciones en que se acuda representado por alguien que tiene ya una formación jurídica básica, que la ley estima se tiene en la etapa final de la carrera de Derecho. Está 
entonces dentro de la discrecionalidad del legislador, a la luz de la Constitución, el señalar los casos en los cuales se puede litigar en causa ajena, aun sin poseer todavía el título. La posibilidad de litigar en causa ajena, para quienes aún no ostentan su título de abogados, y están en los últimos dos años de la carrera, se circunscribe a quienes pertenecen a un consultorio jurídico que tutela, guía y supervisa su actividad, y con el único objeto de brindar posibilidades de acceso a la administración de justicia a quienes, por su situación económica, requieren ese apoyo de las instituciones educativas en el campo del Derecho.

Ahora bien, el proceso de responsabilidad fiscal es un procedimiento administrativo que realizan las Contralorías, el cual busca determinar la responsabilidad del servidor público o particular cuando estos estén en ejercicio de la gestión fiscal y causen por acción u omisión un detrimento patrimonial al Estado. Luego, los señalados como responsables fiscales requieren la defensa técnica de un abogado que vele por sus derechos e intereses ante las Contralorías. Para ello el legislador, a través del artículo primero de la Ley 583 del 2000 numeral 8, facultó a los estudiantes de los consultorios jurídicos del país para que actúen como apoderados en esta clase de procesos estableciendo que las Contralorías deben solicitar de oficio la participación de los estudiantes cuando la Ley así lo disponga.

Así las cosas, es necesario establecer la importancia de la defensa técnica que realizan los estudiantes de los consultorios jurídicos en los procesos de responsabilidad fiscal, cumpliendo así con el mandato constitucional que estipula el acceso a la administración de justicia para todos los ciudadanos del país, garantizándoles el derecho a la igualdad frente a los ciudadanos que si tienen como sufragar los gastos de un abogado que proteja sus derechos e intereses. Desde el Consultorio Jurídico de CECAR, durante los últimos años la Contraloría General de la República Gerencia Departamental de Sucre y la Contraloría Departamental de Sucre, han solicitado de oficio el apoyo de los estudiantes que están realizando su práctica jurídica para defender a personas inmersas en procesos de responsabilidad fiscal, garantizándoles de esta manera una defensa técnica.

Con el propósito de desarrollar este tema, nos hemos planteado la siguiente pregunta problema: ¿Cuál es la importancia de la defensa técnica en procesos de responsabilidad fiscal ejercida por los estudiantes 
de consultorio jurídico en el municipio de Sincelejo-Sucre en los años 2016, 2017 y 2018?; para poder darle respuesta a esta pregunta, nos hemos fijado un objetivo general: Determinar la importancia de la defensa técnica en procesos de responsabilidad fiscal, ejercida por los estudiantes de consultorio jurídico en el municipio de Sincelejo-Sucre, en los años 2016, 2017 y 2018; en aras de darle cumplimiento a este objetivo, se torna necesario plantearnos los siguientes objetivos específicos:

1. Analizar las normas jurídicas que regulan el proceso de responsabilidad fiscal en Colombia en relación con la defensa de oficio realizada por los estudiantes del consultorio jurídico de CECAR.

2. Establecer la competencia legal para asumir la defensa técnica de oficio en los procesos de responsabilidad fiscal por estudiantes de los consultorios jurídicos.

3. Realizar un análisis de los procesos de responsabilidad fiscal asumidos por los estudiantes del consultorio jurídico de CECAR en los años 2016, 2017 y 2018.

\section{Metodología}

Investigación de tipo jurídico, de carácter descriptivo y con un enfoque cualitativo, nos hemos propuesto analizar las normas jurídicas que regulan lo referente al proceso de responsabilidad fiscal en Colombia, examinaremos lo establecido por las normas vigentes y las decisiones tomadas por los honorables magistrados de la Corte Constitucional a través de sentencias juridiciales con respecto a la competencia legal para asumir la defensa técnica en los procesos de responsabilidad fiscal; teniendo en cuenta principalmente el papel que desempeñan los estudiantes adscritos a los consultorios jurídicos en la asignación de oficio como apoderados de personas inmersas en un proceso de este tipo.

Para darle desarrollo al tercer objetivo se hace necesario analizar las estadísticas de los años 2016, 2017 y 2018 de los procesos de responsabilidad fiscal en los cuales han sido partícipes como apoderados los estudiantes del consultorio jurídico de CECAR, solicitados de oficio por 
la Contraloría General de la República Gerencia Departamental de Sucre y en la Contraloría Departamental de Sucre.

Las fuentes utilizadas son secundarias puesto que la información de las estadísticas reposa en los archivos del consultorio jurídico de CECAR. Las normas que regulan nuestro tema planteado son de conocimiento público al igual que las decisiones tomadas por los magistrados de la Corte Constitucional en sentencias judiciales, las cuales se encuentran en las páginas web de la Corte Constitucional y del Congreso de la República; todo esto para darle cumplimiento a los nuestros objetivos específicos.

\section{Procedimiento de responsabilidad fiscal en Colombia en relación con la defensa de oficio realizada por los estudiantes del consultorio jurídico de CECAR}

La responsabilidad fiscal en Colombia gira en torno a dos aspectos principales: la gestión fiscal, que se sintetiza en el manejo o administración de recursos públicos por parte de servidores públicos o particulares en orden a cumplir los fines del Estado y la existencia de un daño patrimonial al Estado. En este orden de ideas, quien no realice gestión fiscal, no puede ser susceptible de atribuir responsabilidad fiscal, figura jurídica a través de la cual el Estado hace un control posterior (Vasquez Miranda, 2000, pág. 38) sobre el buen manejo del dinero público en beneficio del interés general. Así mismo, habrá responsabilidad fiscal siempre y cuando se encuentre suficientemente demostrada la existencia de un detrimento económico al erario público. El marco normativo del proceso de responsabilidad fiscal en Colombia, a través del cual se busca el resarcimiento económico del daño causado al patrimonio estatal, está determinado por los artículos 29 y 290 de la Constitución política de 1991, así como los artículos 267 y 268 del mismo cuerpo normativo que describe las funciones de la Contraloría entidad encargada del seguimiento y aplicación de la Ley en estos procesos. A nivel legal, se encuentra regido por la Ley 610 del 2000, la cual desarrolla todo el aspecto sustancial y procesal de la materia. También la Ley 1474 de 2011 artículos 97 y siguientes, que contempla el procedimiento verbal y la Ley 267 del 2000 que regula la organización y funcionamiento del ente de control. 
En efecto, en Colombia existen actualmente dos tipos de procedimientos a través de los cuales se juzga la responsabilidad fiscal de los investigados. Se trata de un procedimiento escritural y otro verbal por audiencias. El primero de ellos se regula en la Ley 610 del 2000 y el siguiente a través de Ley 1474 de 2011 artículos 97 y siguientes. En ambos tipos de procedimientos pueden requerirse los servicios de los estudiantes del consultorio jurídico de CECAR como apoderados de oficio para la defensa de los implicados. A continuación, se realizará un análisis de las disposiciones normativas que fijan proceso de responsabilidad fiscal y la participación de los estudiantes del consultorio jurídico en cada una de las etapas. El proceso de responsabilidad fiscal inicia de oficio, a raíz de una denuncia ciudadana o por solicitud de las entidades vigiladas. Al iniciar de oficio se da como consecuencia de una auditoría fiscal (Vasquez Miranda, 2000) que realiza la Contraloría en virtud de su función constitucional y legal de control fiscal. A grandes rasgos, los pasos que deben cumplir ambos procedimientos, el verbal y el escritural son: indagación preliminar, de apertura, imputación de responsabilidad fiscal, fallo con o sin responsabilidad fiscal, recursos procedentes, grado de consulta. Además, se aclara que en cualquier etapa del proceso, la Contraloría puede disponer su archivo, el cual siempre deberá ser revisado en grado de consulta por el superior jerárquico de la dependencia a cargo de la investigación (artículo 18, Ley 610 del 2000).

$\mathrm{Al}$ adentrarnos en las causales de archivo de los procesos, se pueden apreciar diferentes posiciones de defensa que pueden ser invocados en desarrollo del proceso. El auto de archivo podrá emitirse en las siguientes situaciones: Cuando se acredite el resarcimiento del daño patrimonial, es decir, cuando los investigados, o terceros que podrían ser las aseguradoras, paguen el valor del detrimento en cualquier estado del proceso o demuestren su resarcimiento total, lo que podría implicar no solo pago de dinero, también devolución de bienes a la entidad afectada, la compensación o la culminación del objeto contractual bajo los términos del contrato por cuyo incumplimiento se inició el proceso por detrimento patrimonial al estado.

Así mismo, cuando se pruebe la inexistencia real de un daño patrimonial, esto ocurre cuando la Contraloría basada en los hallazgos da apertura el procedimiento por responsabilidad fiscal pero los implicados logran probar a través de medios probatorios idóneos, que 
materialmente no existió tal detrimento. Es posible también, que en virtud de un procedimiento sancionatorio administrativo, los investigados y/o las aseguradoras que amparaban los riesgos emanados de los contratos, hayan pagado por cualquier irregularidad contractual, sea por la no entrega de los productos con las especificaciones de calidad y cantidad contratadas, por la no culminación del objeto contractual, por la desviación o apropiación de dineros públicos, no cumplimiento de los términos estipulados, no pago de salarios y prestaciones sociales de los trabajadores, buen manejo y correcta inversión del anticipo, y en general, el mal manejo del dinero público, traduciéndose lo anterior en una inexistencia real de un daño patrimonial en virtud del resarcimiento del mismo.

Se puede observar que en algunos casos, el detrimento patrimonial puede tener como causa el incumplimiento de un contrato estatal, en dicho caso, deberá debatirse la responsabilidad entre aquellas personas que realicen gestión fiscal, sean los ordenadores del gasto, servidores públicos y contratistas. En dichos casos, es posible que se haya llevado a cabo la declaratoria de incumplimiento, y la imposición de multa y sanciones contempladas en el artículo 86 de la Ley 1474 de 2011, pudiendo suponer la existencia de una cosa juzgada. A pesar de que existan posiciones diferentes al respecto, unas de ellas a favor de tener como cosa juzgada el incumplimiento debatido en sede de la antes llamada vía gubernativa y otros que sostienen que se trata de procedimientos con finalidades disímiles, bastaría revisar cada caso concreto para así determinar la existencia o no de un daño patrimonial al Estado, así como el resarcimiento del mismo a la entidad estatal que promovió el procedimiento administrativo sancionatorio.

Otro evento en el cual procede dictar auto de archivo se da cuando la actuación que generó el hallazgo fiscal no comporta el ejercicio de gestión fiscal. De hecho, tal como se mencionó al inicio de este escrito, el ejercicio de la gestión fiscal es el centro de la declaratoria de responsabilidad fiscal. Luego, alrededor de esta temática se debatirán las posiciones de defensa de los investigados, algunos tratando de aclarar que su actividad no representa gestión fiscal alguna, al ser particulares o por la ausencia de carácter público de los recursos manejados. Un ejemplo claro de esta circunstancia lo puede configurar el pago anticipado, situación que genera gran debate pues, al contratista se le da un dinero de origen público como pago anticipado, pero que al pasar a su patrimonio particular deja de 
tener este carácter, teniendo a bien el contratista gastarlo o invertirlo a su arbitrio, pues configura su ganancia, su retribución por la labor realizada. Es claro que se trata de un dinero que deja de ser público, y que por tanto, su administración no representa para los particulares ejercicio de gestión fiscal, la discusión jurídica se general al momento de exigir su devolución. Diferente al anticipo, situación en la que la entidad estatal entrega al contratista de manera adelantada el dinero necesario para el cumplimiento del contrato, dinero de origen público que no deja de tener este carácter, pues su propósito es lograr el objeto del contrato el cual va acorde al bien común y los fines del Estado.

Otras causales para ordenar el archivo del proceso es la comprobación de una de las causales excluyentes de responsabilidad, como la fuerza mayor o caso fortuito, hecho de un tercero. También podrá invocarse la caducidad de la acción fiscal, pasados 5 años de la ocurrencia del hecho generador del daño sin emitir auto de apertura, o prescripción de la responsabilidad fiscal, pasados 5 años desde que fue emitido el auto de apertura sin fallo condenatorio ejecutoriad, ambos eventos descritos en el artículo 9 de la ley 610 del 2000. Todas las situaciones antes descritas podrían hacer parte de la defensa técnica que deban ejercer los estudiantes de consultorio jurídico de CECAR en su labor de apoderados de oficio solicitados por la Contraloría, claro está, con el debido acompañamiento del tutor o asesor del área, que se trata de un docente que realiza el acompañamiento disciplinar a los estudiantes.

Ahora, al enfocarnos nuevamente en las etapas procesales, la Contraloría, al recibir los hallazgos fiscales tiene dos posibilidades, la primera es emitir auto de apertura, en este caso el proceso se tramitará de manera escritural. La otra opción es emitir auto de apertura e imputación, caso en el cual el proceso se tramitará por el procedimiento verbal. Ésta, además de agotar el proceso en audiencias orales, es la diferencia más marcada entre ambos procedimientos. Según el artículo 97 de la Ley 1474 de 2011, sólo cuando existen méritos suficientes deberá dictarse en un solo auto tanto la apertura del proceso como la imputación de la responsabilidad fiscal. Esto tiene implicaciones a nivel probatorio, pues si nos vamos al artículo 48 de la Ley 610 del 2000, este indica que se dicta auto de imputación escritural cuando esté demostrado objetivamente el daño o detrimento patrimonial al Estado, es decir, cuando existan medios probatorios que comprometan 
la responsabilidad de los implicados, pues con el auto de apertura lo que se busca es anunciar formalmente la existencia del procedimiento basado en el hallazgo fiscal originado en la indagación preliminar, la queja, el dictamen o el ejercicio de cualquier acción de vigilancia o sistema de control, y adicionalmente iniciar el recudo de pruebas al encontrar establecida la existencia de un daño e indicios serios sobre los posibles autores del mismo.

Al notificarse de la apertura de un proceso de responsabilidad fiscal, el investigado tiene la posibilidad de solicitar que se le escuche en exposición libre y espontánea (art. 42, Ley 610 del 2000). Esta oportunidad inicial de defensa se omite para el investigado en contra del cual, al existir pruebas conducentes sobre el daño patrimonial causado, se expida auto de apertura e imputación, en cuyo caso pasará a presentar descargos directamente. Cabe destacar que, en el procedimiento escritural, tal como lo contempla el artículo 42 de la Ley 610 del 2000, sin haberse escuchado la versión libre del investigado o sin que ante su ausencia, se le haya designado apoderado de oficio, no podrá seguirse con la etapa de imputación. Así pues, es en esta etapa de los procesos escriturales principalmente donde ha de solicitarse al consultorio jurídico de CECAR el acompañamiento en defensa de los investigados, teniendo la oportunidad de ejercer su defensa desde el inicio del proceso.

Continuando el estudio del procedimiento, en el escritural, luego de emitir auto de apertura y de escuchar en versión libre al implicado o haber nombrado apoderado de oficio, se continúa con el auto de imputación, cuyo contenido ya fue mencionado al hablar de sus implicaciones en el procedimiento oral. En ambos procedimientos al encontrarse en etapa de imputación se procede a atender los descargos escritos u orales de los investigados, oportunidad en la cual se deben aportar y solicitar la práctica de pruebas que consideren necesarias para su defensa. La Contraloría decidirá sobre la práctica de las mismas en auto contra el cual proceden los recursos de Ley. Surtida esta etapa, el ente de control a través del funcionario competente procederá a dictar fallo con responsabilidad fiscal siempre y cuando exista certeza sobre la existencia del daño y su cuantía, de la actuación del gestor fiscal y del nexo causal entre ambos, lo que determinaría su responsabilidad fiscal (artículo 53, Ley 610 del 2000).

En caso de no existir certeza sobre los elementos antes mencionados, se procederá a dictar fallo sin responsabilidad, decisión que deberá someterse 
a revisión en grado de consulta. Se agrega que en el mencionado grado de consulta se revisarán las decisiones de archivo, y fallo sin responsabilidad fiscal, así como en el evento en que se dicta fallo con responsabilidad fiscal y el condenado al estar ausente haya sido representado por apoderado de oficio (artículo 18, Ley 610 del 2000), ello significa que siempre que participen los estudiantes del consultorio jurídico en defensa técnica jurídica de los investigados ausentes, los fallos serán revisados en grado de consulta para verificar la protección de sus derechos fundamentales y del interés público. De esta manera se observa cómo se desarrolla el proceso de responsabilidad fiscal en Colombia y los momentos de especial participación de los estudiantes del consultorio jurídico de CECAR como defensores de oficio.

\section{Competencia legal de los estudiantes de consultorio jurídico en los procesos de responsabilidad fiscal}

El Presidente de Colombia Misael Pastrana Borrero elegido popularmente para el período de 1970-1974, en su segundo año de mandato y haciendo uso de sus facultades extraordinarias, crea el estatuto de la abogacía a través del Decreto 196 de 1971. De esta manera, por primera vez en la historia de Colombia le dieron competencia a los estudiantes de los consultorios jurídicos de las facultades del país. A través de este decreto se reguló la creación de consultorios jurídicos por parte de las Facultades de Derecho y en qué casos los estudiantes de los dos últimos años lectivos podrían fungir como apoderados. Así fue como se estableció en el artículo 30 numeral 8 que las Contralorías de oficio podrían solicitar a los consultorios jurídicos la participación de los estudiantes para que ejercieran la defensa técnica en los procesos de responsabilidad fiscal cuando fuera necesario de acuerdo a lo establecido por la ley. Veintinueve años después de la expedición del estatuto de la abogacía, el Congreso de la República de Colombia a través de la Ley 583 de 2000 en su artículo 1, modificó el artículo 30 del decreto 196 del 1971 antes mencionado, conservando la competencia legal otorgada a los estudiantes de los consultorios jurídicos de las facultades de derecho del país en los procesos de responsabilidad fiscal iniciados por las Contralorías, regulando que son las Contralorías del país quienes deben hacer la solicitud de oficio ante las oficinas de los Consultorios Jurídicos en los casos que fuere necesario, con la finalidad 
de brindarle a él o los implicados un debido proceso como lo consagra la Constitución Política.

De otra parte, el artículo 42 de la ley 610 de 2000 consagra la garantía de defensa que se le debe dar a un implicado en un procesos de responsabilidad fiscal. Cuando este conozca que existe una indagación preliminar en su contra debe dar una versión libre de la investigación que se ha iniciado, para lo cual puede llevar un apoderado privado, pues tiene esta posibilidad en ejercicio de su derecho de defensa, sin embargo, el acompañamiento por parte de una apoderado de confianza es decisión del implicado y la ausencia del aquel no invalidará lo actuado. El funcionario encargado de la indagación preliminar está obligado a solicitar un apoderado de oficio solo en casos en que el investigado no asista a la diligencia o no pueda ser localizado. Así pues, de acuerdo con el mencionado artículo, no se podrá dictar el auto de imputación de responsabilidad fiscal cuando al implicado no se le ha escuchado su versión libre, cuando no comparezca a la diligencia, no se le ha nombrado un apoderado de oficio o cuando no ha podido ser localizado. Resulta desgastante para un investigador no poder continuar con la siguiente etapa procesal del proceso de responsabilidad fiscal en los casos en que el investigado no se presente o no pueda ser localizado, porque su investigación no tendría avances, es por esto que el legislador consagró la competencia legal de los estudiantes de los consultorios jurídicos para los procesos de responsabilidad fiscal en aras darle desarrollo y así resarcir el daño patrimonial causado al Estado.

En la parte introductoria de este capítulo del libro mencionamos que la norma que regula la competencia legal de los estudiantes de los consultorios jurídicos de las facultades de derecho del país en los procesos de responsabilidad fiscal, ha tenido muchas solicitudes de declaratorias de inexequibilidad ante la Corte Constitucional por abogados litigantes que han demandado la norma actual porque ellos consideran que existe una violación a algunos artículos de nuestra Constitución Política, a lo que la Corte en muchas sentencias ha reiterado su decisión de no declarar inexequible la norma que faculta a los estudiantes para que se desempeñen como abogados en algunos procesos. En efecto, en la sentencia SU 044 DE 1995 (Corte Constitucional de Colombia, 1994)en su parte final la Corte establece lo siguiente: 
La Sala concluye señalando que los numerales acusados del artículo 1 de la Ley 583 de 2000, se ajustan a las disposiciones constitucionales y desarrollan principios constitucionales que garantizan derechos como el debido proceso, la solidaridad, el acceso a la administración de justicia, lo cual llevará a declarar la exequibilidad de las disposiciones demandadas (...), la Sala Plena de la Corte Constitucional, administrando justicia en nombre del pueblo y por mandato de la Constitución, decide: Declarar EXEQUIBLES los apartes demandados de los numerales 2, 4, 5, 7, 8 y 9 del artículo 1 de la Ley 583 de 2000, siempre que los estudiantes que actúen en su desarrollo ejerzan el Derecho bajo la supervisión, la guía y el control de las instituciones educativas a las cuales pertenecen.

En consecuencia, los estudiantes en la actualidad se encuentran facultados para litigar en causa ajena como abogados de pobres (artículo 1, Decreto 196 de 1971) en los procesos de responsabilidad fiscal en donde tendrán plena competencia para la representación y defensa de los investigados en los casos asignados con la orientación del docente tutor a cargo del área en el Consultorio jurídico al cual se encuentren adscritos.

\section{¿Cómo se escogen los estudiantes que serán apoderados de oficio solicitados por las contralorías en los procesos de responsabilidad fiscal?}

De acuerdo al protocolo establecido por el Consultorio Jurídico de CECAR, el proceso de escogencia de los apoderados de los procesos de responsabilidad fiscal es el siguiente:

1. La secretaria del consultorio jurídico de CECAR recepciona la solicitud de oficio enviada por parte de la Contraloría General de la República Gerencia Departamental de Sucre o de la Contraloría departamental de Sucre, la cual es un documento formal. (ver anexo 1)

2. El oficio es llevado hasta la oficina del monitor o monitora de trámites procesales, el cual es el encargado de escoger el o los apoderados de acuerdo a la solicitud, para así de esta manera cumplir con el mandato legal. 
3. Los estudiantes de Consultorio jurídico de CECAR realizan turnos de una hora y treinta minutos (01:30) en el Consultorio Jurídico III, llamado trámites procesales, que es cursado por los estudiantes de noveno semestre de la Facultad de Derecho.

4. Una vez la secretaria hace llegar hasta el monitor de Consultorio Jurídico de Trámites Procesales, este último se encarga de escoger a cualquier estudiante que esté en turno realizando su práctica jurídica, de esta manera se hace la designación del proceso de responsabilidad fiscal en el cual las Contralorías hacen solicitud de oficio de apoderados, mediante un oficio realizado por el monitor de trámites procesales y entregado al estudiante escogido (ver anexo 2).

5. Para poder posesionarse en la Contraloría como apoderado del proceso de responsabilidad fiscal solicitado, el estudiante necesita una autorización que realiza el monitor de trámites procesales, la cual es revisada por el coordinador de consultorio jurídico y por último aprobada firmada por la directora del mismo (ver anexo 3).

6. Una vez el estudiante tenga en su poder la designación y autorización por parte del consultorio jurídico de CECAR del proceso de responsabilidad fiscal en el que una de las Contralorías solicita apoderado de oficio, este debe dirigirse hasta donde el asesor de derecho público especialista en el tema de responsabilidad fiscal para que reciba una asesoría de cómo se va a desempeñar dentro del proceso.

7. El estudiante debe dirigirse hasta la Contraloría donde repose el proceso para el cual fue designado a realizar la posesión del mismo y obtener todo el expediente del proceso para iniciar con su actuación procesal, momento en el cual recibe el archivo digital del proceso y se posesiona como apoderado del mismo (ver anexo 4 y 5 ).

8. Siempre que sea necesario el estudiante recibirá las pautas necesarias de acuerdo al proceso por parte del asesor encargado y deberá presentar un informe mensual ante el monitor de trámites procesales, para que este último haga el respectivo seguimiento 
de su actuación frente al proceso de responsabilidad fiscal que le fue designado. Una vez finalice el proceso también debe ser comunicado con un respectivo formato de informe creado por el consultorio jurídico y que debe ser desarrollado por el estudiante (ver anexo 6).

\section{Matriz de estadísticas de los años 2016, 2017 y 2018 de los procesos de responsabilidad fiscal, en los cuales han sido apoderados los estudiantes del consultorio jurídico de CECAR}

En el año 2016 fueron recibidas y atendidas 24 solicitudes de designación de apoderado de oficio para procesos de responsabilidad fiscal, de las cuales solo una fue presentada por la Contraloría general del departamento de Sucre y las restantes por la Contraloría general gerencia departamental de Sucre. Por su parte en el año 2017 fueron recibidas y atendidas 4 solicitudes, todas ellas por parte de la Gerencia departamental de Sucre. Adicionalmente, en el primer semestre del año 2018 fueron recibidas 16 solicitudes de designación de apoderado de oficio, 7 de ellas presentadas por parte de la Contraloría general del departamento de Sucre y las restantes por la Contraloría general gerencia departamental de Sucre.

Con lo anterior se evidencia el aporte del Consultorio jurídico de la Corporación universitaria del Caribe CECAR como instrumento de proyección social, a través del cual se brinda a la población local un apoyo, no sólo a nivel de asesoría jurídica, sino también en su defensa técnica, pues en los procesos de responsabilidad fiscal el estudiante, bajo la orientación del docente asesor, actúa como apoderado de oficio velando por la protección del derecho de defensa y debido proceso de los presuntos responsables fiscales, cumpliendo con una labor social en consonancia con la Misión institucional.

Tabla 1

Contraloría que hizo la solicitud de oficio Año 2016

FECHA

CONTRALORÍA QUE HIZO LA SOLICITUD DE OFICIO
15 de febrero de 2016

22 de febrero de 2016
Contraloría General de la República, Gerencia Departamental de Sucre

Contraloría General de la República, Gerencia Departamental de Sucre 
FECHA

22 de febrero de 2016

08 de marzo DE 2016

29 de marzo de 2016

05 de abril de 2016

05 de abril de 2016

05 de abril de 2016

05 de abril de 2016

05 de abril de 2016

12 de abril de 2016

12 de abril de 2016

23 de agosto de 2016

23 de agosto de 2016

23 de agosto de 2016

23 de agosto de 2016

29 de agosto de 2016

05 de octubre de 2016

05 de octubre de 2016

05 de octubre de 2016
CONTRALORÍA QUE HIZO LA SOLICITUD DE OFICIO

Contraloría General de la República, Gerencia Departamental de Sucre

Contraloría General de la República, Gerencia Departamental de Sucre

Contraloría General de la República, Gerencia Departamental de Sucre

Contraloría General de la República, Gerencia Departamental de Sucre

Contraloría General de la República, Gerencia Departamental de Sucre

Contraloría General de la República, Gerencia Departamental de Sucre

Contraloría General de la República, Gerencia Departamental de Sucre

Contraloría General de la República, Gerencia Departamental de Sucre

Contraloría General de la República, Gerencia Departamental de Sucre

Contraloría General de la República, Gerencia Departamental de Sucre

Contraloría General del Departamento de Sucre

Contraloría General de la República, Gerencia Departamental de Sucre

Contraloría General de la República, Gerencia Departamental de Sucre

Contraloría General de la República, Gerencia Departamental de Sucre

Contraloría General de la República, Gerencia Departamental de Sucre

Contraloría General de la República, Gerencia Departamental de Sucre

Contraloría General de la República, Gerencia Departamental de Sucre

Contraloría General de la República, Gerencia Departamental de Sucre 
FECHA

CONTRALORÍA QUE HIZO LA SOLICITUD DE OFICIO

24 de octubre de 2016

31 de octubre de 2016

01 de noviembre de 2016

03 de noviembre de 2016 Departamental de Sucre

Contraloría General de la República, Gerencia Departamental de Sucre

Contraloría General de la República, Gerencia Departamental de Sucre

Contraloría General de la República, Gerencia
Contraloría General de la República, Gerencia Departamental de Sucre

Fuente: creación propia.

Tabla 2

Contraloría que hizo la solicitud de oficio Año 2017
CONTRALORÍA QUE HIZO LA SOLICITUD DE OFICIO

21 de marzo de 2017

Contraloría General de la República, Gerencia Departamental de Sucre

21 de marzo de 2017

Contraloría General de la República, Gerencia Departamental de Sucre

21 de marzo de 2017

Contraloría General de la República, Gerencia Departamental de Sucre

29 de agosto de 2017

Contraloría General de la República, Gerencia Departamental de Sucre

Fuente: creación propia.

Tabla 3

Contraloría que hizo la solicitud de oficio Año 2018

FECHA

26 de febrero de 2018

01 de marzo de 2018

05 de marzo de 2018
CONTRALORÍA QUE HIZO LA SOLICITUD DE OFICIO

Contraloría General del Departamento de Sucre

Contraloría General del Departamento de Sucre

Contraloría General de la República, Gerencia Departamental de Sucre 
05 de marzo de 2018

16 de abril de 2018

16 de abril de 2018

17 de abril de 2018

17 de abril de 2018

17 de abril de 2018

17 de abril de 2018

17 de abril de 2018

08 de mayo de 2018

21 de mayo de 2018

21 de mayo de 2018

21 de mayo de 2018

21 de mayo de 2018

Contraloría General de la República, Gerencia Departamental de Sucre

Contraloría General de la República, Gerencia Departamental de Sucre

Contraloría General de la República, Gerencia Departamental de Sucre

Contraloría General de la República, Gerencia Departamental de Sucre

Contraloría General de la República, Gerencia Departamental de Sucre

Contraloría General de la República, Gerencia Departamental de Sucre

Contraloría General de la República, Gerencia Departamental de Sucre

Contraloría General de la República, Gerencia Departamental de Sucre

Contraloría General del Departamento de Sucre Contraloría General del Departamento de Sucre Contraloría General del Departamento de Sucre Contraloría General del Departamento de Sucre Contraloría General del Departamento de Sucre

Fuente: creación propia.

\section{Conclusiones}

A través del presente trabajo se logró determinar la importancia de la defensa técnica en procesos de responsabilidad fiscal, ejercida por los estudiantes de consultorio jurídico de CECAR en el municipio de SincelejoSucre, en los años 2016, 2017 y 2018, pudiendo evidenciar los posibles argumentos de defensa que el estudiante, estaría en la posición de plantear a lo largo del proceso de responsabilidad fiscal sea verbal o escritural de acuerdo a lo establecido en el ordenamiento normativo colombiano. También se pudo establecer la competencia que tienen los estudiantes para actuar como apoderados de oficio en este tipo de procesos, la cual es una competencia legal que va en armonía con los preceptos constitucionales 
tal como lo ha sostenido la Corte Constitucional ante las demandas que solicitan la inexequibilidad del artículo que prevé dicha facultad. La defensa realizada por los estudiantes en los procesos de responsabilidad fiscal debe tenerse como constitucional bajo el entendido de que esta será realizada siempre bajo la supervisión, guía y control de la institución educativa lo cual se da en el consultorio jurídico de CECAR a través de la orientación del docente asesor y del monitor del área. Todo lo anterior en garantía del derecho al debido proceso y defensa técnica de los investigados.

Esto demuestra la seriedad y profesionalismo con el cual se aceptan estos encargos legales y se desarrolla la defensa asignada en la Corporación, siguiendo los protocolos de manera estricta y estando atento a las actuaciones y los informes presentados por los estudiantes. Por último, con el presente trabajo se evidenció el aporte del consultorio jurídico como ente de proyección social al realizar la labor de defensa técnica de las personas que así lo requieran en los casos estipulados en la Ley.

\section{Referencias}

Congreso de la república de Colombia, Ley 610 (Por la cual se establece el trámite de los procesos de responsabilidad fiscal de competencia de las contralorías 15 de Agosto de 2000).

Congreso de la república de Colombia, Ley 583 (Por la cual se modifican los artículos 30 y 9 del Decreto 196 de 197112 de Junio de 2000).

Congreso de la república de Colombia, Ley 1474 (Por la cual se dictan normas orientadas a fortalecer los mecanismos de prevención, investigación y sanción de actos de corrupción y la efectividad del control de la gestión pública. 12 de Julio de 2011).

Corte Constitucional de Colombia, SU 044 DE 1995 (9 de febrero de 1994). Corte Constitucional de Colombia, C-626 (21 de Noviembre de 1996). Corte Constitucional de Colombia, C-143 de 2001 (7 de Febrero de 2001). Presidencia la república de Colombia- Ministerio de Justicia, Decreto 196 (1 de Marzo de 1971).

Vasquez Miranda, W. (2000). Control Fiscal y auditoría de Estado en Colombia. Bogotá: Fundaciónn Universidad de Bogotá Jorge Tadeo Lozano. 